\title{
Protective Effects of Spirulina on the Liver Function and Hyperlipidemia of Rats and Human
}

\author{
Mostafa Mohamed El-Sheekh ${ }^{1 *}$, Saied Mohamed Hamad ${ }^{2}$ and Mahmoud Gomaa ${ }^{1}$ \\ ${ }^{1}$ Botany Department; Faculty of Science; Tanta University; Tanta - Egypt. ${ }^{2}$ Clinical Pathology Department; Faculty \\ of Medicine; Tanta University; Tanta - Egypt
}

\begin{abstract}
In the present study, the effects of Spirulina on subchronic treatments (two weeks) of hyperlipidemia and liver function of the rats and humans were investigated. The hyperlipidemia was induced in the rats using $25 \%$ of soya bean oil and $25 \%$ butter. The butter induced more hyperlipidemia than soya bean oil. Spirulina was used at the concentrations of 0, 2.5, 5.0 and $10 \%$ of diet weight of the rats. The decrease in hyperlipidemia by Spirulina was dependent on its concentration in the diet. In case of human studies, about four g/day of Spirulina was taken via oral administration by Egyptian volunteers patients with hyperlipidemia. Spirulina decreased the levels of hyperlipidemia in these patients. The effects were dependent on the amount and number of administered dose of Sprirulina. The results suggested that the Spirulina treatment could induce marked reduction of aminotransferase through correcting lipid profile and increasing high density lipoprotein.
\end{abstract}

Key words: Spirulina, Hyperlipidemia, Protective effects, Liver functions

\section{INTRODUCTION}

Hyperlipidemia is the presence of high, or abnormal levels of lipids and/or lipoproteins in the blood, or elevation of lipids in plasma. Several studies have shown that an intimate correlation exists between coronary diseases and high levels of lipoprotein (Shattat et al. 2010). Lipids, such as cholesterol and triglycerides, are insoluble in plasma and circulating lipid are carried on by lipoproteins that transport them to various tissues for energy utilization, lipid deposition, steroid hormone production, and bile acid production. Lipoprotein consists of esterified and unesterified cholesterol, triglycerides, and phospholipids, and protein, which consist mainly of apolipoproteins, or apoproteins (Rader et al. 1994).

Disturbance in lipid profile results in lipid disorders including 1) familial combined hyperlipidemia $(\mathrm{FCH})$, caused by polymorphisms in the molecules and enzymes that participate in lipoprotein metabolism, such as ApoCII and ApoCIII and CETP (cholesterylester transferring protein) and acquired combined hyperlipidemia, which is common in the patients who suffer from other diseases from the metabolic syndrome (diabetes mellitus type II and hypertension). Excessive free fatty acid production by various tissues leads to increased VLDL synthesis by the liver. Initially, most of VLDL is converted into LDL (James et al. 2006).

Fatty liver, known as fatty liver disease (FLD) such as steatorrhoeic hepatosis, or steatosis hepatitis, is a reversible condition where large vacuoles of triglyceride fat accumulate in liver cells via the process of steatosis (Reddy and Rao 2006; Bayard et al. 2006). Fatty liver is often associated with alcoholic liver disease,

*Author for correspondence: mostafaelsheekh@yahoo.com 
hyperinsulinemia, and insulin-resistance. Accordingly, it is most often observed in alcoholics, obese persons, and diabetic patients. It is also frequently caused by pregnancy, malnutrition, chemical intoxication, drug and viral hepatitis, and intestinal bypass surgery (Riely 1987; Doherty et al. 1991; Guha-Mazumder 2001; Altlparmak et al. 2005; Adams and Talwalkar 2006).

Heart diseases remain the leading cause of death for both men and women of all races and ethnicities. It is expected that large proportion of elderly individuals would suffer from heart diseases. In men over the age of 65 , for example, nearly one-half of all deaths are attributed to heart diseases. In this regard, the prevalence of hyperlipidemia is as high as $80-88 \%$ as compared to approximately $40-48 \%$ in age-matched controls without coronary diseases (Carroll et al. 2005; Boekholdt 2007). A variety of factors, often acting in combination, are associated with an increased risk for atherosclerotic plaques in coronary arteries and other arterial beds. Hypercholesterolemia is one of the major risk factors for heart diseases, including in those over the age of 65 (Lewington et al. 2007).

Spirulina is free-floating filamentous cyanobacteria characterized by the cylindrical, multicellular trichomes in an open left-hand helix which can be found in tropical and subtropical lakes in Africa, Asia and South and Central America (Vonshak 1997). It has high protein content, $60-70 \%$ of its dry weight, whose nutritive value is related to the quality of amino acid. It contains all essential amino acids, including leucine, isoleucine and valine, with reduced amounts of methionine, cysteine, and lysine when compared to the proteins of meat, eggs, and milk (Babadzhanov et al. 2004). It is, however, superior to typical plant protein, such as those derived from legumes (Babadzhanov et al. 2004). It also contains a relative high concentration of provitamin A, vitamin B12 and $\beta$-carotene, vitamin B1 (thiamine), B2 (riboflavin), B3 (nicotinamide), B6 (pyridoxine), B9 (folic acid), vitamin C, vitamin D, and vitamin E. Spirulina have $4-7 \%$ lipids, essential fatty acids and $\omega-3$ and $\omega-6$ polyunsaturated fatty acids, including $\gamma$ linolenic acid, $\alpha$-linolenic acid, linoleic acid, stearidonic acid, eicosapentaenoic acid, docosahexaenoic acid, and arachidonic acid (Sánchez 2007; Huang et al. 2007). Spirulina also is a rich source of several minerals, including potassium, calcium, chromium, copper, iron, magnesium, manganese, phosphorus, selenium, sodium, and zinc (Tokusoglu and Uunal 2003).

Administration of Spirulina has been found to lower the heart damage caused by chemotherapy (Khan et al. 2005), reduces the severity of strokes and improves recovery of movement after a stroke (Wang et al. 2005), and reverses age-related declines in memory and learning. Spirulina also has been found to prevent and treat hay fever through increase in immunological activities (Chen et al. 2005). In view of the above, this work aimed at investigating the protective effect of Spirulina on hyperlipidemia and liver function in a preclinical rat model as well as in human.

\section{MATERIALS AND METHODS}

\section{Culture medium and growth conditions for Spirulina platensis}

The strain of Spirulina platensis was kindly supplied from the culture collection of Mansoura University, Faculty of Science, Mansoura, Egypt. The medium used for the Spirulina cultivation was Zarrouk's medium (Zarrouk 1966). Erlenmeyer flasks $(250 \mathrm{~mL})$ contained $150 \mathrm{~mL}$ of Zarrouk's medium were sterilized in an autoclave at $1.5 \mathrm{~atm}$. for $20 \mathrm{~min}$. After cooling, the flasks were inoculated with $15 \mathrm{~mL}$ of the pre-culture organisms and incubated under continuous fluorescent light of 2500 lux. The cultures flasks were aerated with sterile air mixed with $3 \% \mathrm{CO}_{2}$ to accelerate cyanobacterial growth. The rate of gas was regulated by means of plastic valves (Zarrouk 1966).

\section{Determination of dry weight}

A definite volume of cyanobacterial suspension $(200 \mathrm{~mL})$ was centrifuged at $1,077 \mathrm{xg}$ for $10 \mathrm{~min}$. The precipitated cells were washed two times with distilled water and dried overnight in an oven at $65^{\circ} \mathrm{C}$ till constant weight. The data were given as $\mathrm{g} / 100 \mathrm{~mL}$.

\section{Application on experimental animals}

Adult male rats weighing 99-108 g were obtained from the Faculty of Science, Zoology Department, Tanta University, Tanta, Egypt. The rats were housed at $25^{\circ} \mathrm{C}$ and day and night light according to the time needed for each experiment. 


\section{Natural induction of hyperlipidemia}

The rats were divided into three groups according the types of lipids sources (Young 2001): Group (1): this group was fed on normal standard diet to serve as a control group, which was housed throughout the work under the same conditions of other groups; Group (2): this group was fed on high rich oily diet with the oil percentage about $25 \%$ of total diet and housed for 15 days; Group (3): this group was fed on high rich butter (about $25 \%$ of total diet) and housed for 15 days. The groups fed on high rich fatty diet are listed in Table 1.

Table 1 - The different diets of high rich fats of food (25\% Soybean oil and 25\% Butter) and normal diet used for feeding of rats.

\begin{tabular}{lccc}
\hline Composition & Food Group (1) (Control) gm & Food of Group (2) gm & Food of Group (3) gm \\
\hline Soy protein & 249.7 & 249.7 & 249.7 \\
Vitamins mixture & 10 & 10 & 10 \\
Choline butyrate & 2.5 & 2.5 & 2.5 \\
Mineral Mixture & 35 & 35 & 35 \\
Soybean oil & 100 & 250 & $-\mathrm{-}$ \\
Butter & ---- & ----- & 250 \\
Sucrose & 602.8 & 452.8 & 452.8 \\
\hline
\end{tabular}

\section{Hyperlipidemia treatment using Spirulina platensis}

The different groups of rats used for induction of hyperlipidemia were treated with dry Spirulina for 21 days at $0,2.5,5$ and $10 \%$ of diet weight.

\section{Blood sampling and serum preparation}

The blood samples were collected in clean dry heparinized test tubes from the retro-orbital plexus using heparinized microcapillary tubes. The tubes were allowed to stand for $15 \mathrm{~min}$ to clot at room temperature and then centrifuged at $3500 \mathrm{rpm}$ for 15 min using Heraeus Sepatech centrifuge (Labofuge 200), the plasma was separated, frozen at $-20^{\circ} \mathrm{C}$ and stored for further determination of the biochemical parameters (Walters and Gerarde 1970).

\section{Application on human - Ethical committee number (FDA approval,Talk Paper \#T81-18)}

About $5 \mathrm{~mL}$ Blood samples were collected in venipuncture into heparinized syringe (Wu et al. 1989) from 20 Egyptian volunteer patients with history of hyperlipidemia, aged from 30 to 60 years (10 males and 10 females). Volunteers were supplied $\left(4 \mathrm{~g} \mathrm{day}^{-1}\right)$ oral uptake of dry Spirulina. Blood samples were collected in the morning after 12-16 $\mathrm{h}$ of fasting and prepared according to guidelines of the Lipid Research Clinic's program Manual of Laboratory Operations.

\section{Biochemical analyses}

Cholesterol and triglycerides level were estimated according to Finley et al. (1978) and Buccolo and David (1973), respectively. High Density Lipoprotein (HDL) was determined by separation method based on the selective precipitation of apoliprotein B-containing lipoproteins (Very Light Lipoprotein, Low Density Lipoprotein and Lpa) by phosphotungsic acid/ $\mathrm{MgCl}_{2}$, sedimentation of the precipitant by centrifugation, and subsequent enzymatic analysis of high density lipoproteins (HDL) according Burstein et al. (1980). Low Density Lipoprotein (LDL) was determined for human and experimental animals by using the following equation (Schumann and Klauke 2003):

$[$ Cholesterol $-\mathrm{HDL}+$ Triglycride/5] $=$ LDL $\mathrm{mg} / \mathrm{dl}$

After samples preparation, total and direct bilirubin were estimated according to Malloy and Evelyn, (1937). Alanine Aminotransferase (SGPT) and serum Aspartate Aminotransferase (SGOT) activities were determined according to the recommendation of the Expert panel of the IFCC (International Federation of Clinical Chemistry), without Pyridoxalphosphat activation according Schumann and Klauke (2003) and Schumann et al. (2002), respectively. The serum proteins and serum albumin levels of the rats groups and human were estimated according to Burtis (1999) and Rodkey (1964), respectively. Serum Alkaline Phosphatase was determined according to Fischbach and Zawta (1992). 


\section{Statistical analysis}

All data were expressed as the mean of three replicates; \pm standard error of the mean statistical analysis was performed using $t$ test using SPSS 15 software.

\section{RESULTS}

Rats liver functions at zero time (start) and after 7, 14 and 21 days with normal diet

The results in Table 2 showed slight changes in different liver functions measured in the rats.
These changes were insignificant as compared to the control group. The highest protein concentration was detected after 7 days of treatment with normal diet; it increased by $9.5 \%$ in comparison with zero time. The albumin level showed no change during the period of the experiment, except that there was a decrease at 7 days by $5 \%$. SGPT showed increases at 7 and at 21 days by 6 and $9 \%$, respectively in comparison with zero time. SGOT showed a slight increase in its level by 14 days. Alkaline phosphates level decrease at 21 days by $9 \%$ and after 14 days by $16 \%$.

Table 2 - Rats liver functions at zero time (start) and after 7, 14 and 21 days with normal diet (control).

\begin{tabular}{clllllll}
\hline Time (day) & Bil. T & Bil. D & Protein & Albumin & SGPT & SGOT & ALK \\
\hline 0 & $0.7 \pm 0.01$ & $0.14 \pm 0.005$ & $7.4 \pm 0.057$ & $4.3 \pm 0.08$ & $8.1 \pm 0.1$ & $7.2 \pm 0.14$ & $9.2 \pm 0.3$ \\
7 & $0.7 \pm 0.02^{*}$ & $0.14 \pm 0.005$ & $8.13 \pm 0.27^{*}$ & $4.1 \pm 0.1^{*}$ & $8.2 \pm 0.2^{*}$ & $7.3 \pm 0.18^{*}$ & $9.5 \pm 0.2^{* *}$ \\
14 & $0.7 \pm 0.01^{*}$ & $0.15 \pm 0.005$ & $7.36 \pm 0.20^{*}$ & $4.2 \pm 0.08^{*}$ & $8.4 \pm 0.2^{*}$ & $8.2 \pm 0.25^{*}$ & $7.7 \pm 0.1^{* *}$ \\
21 & $0.7 \pm 0.01^{*}$ & $0.14 \pm 0.005$ & $7.43 \pm 0.20^{*}$ & $4.3 \pm 0.05^{*}$ & $8.1 \pm 0.2^{*}$ & $7.2 \pm 0.3^{*}$ & $8.4 \pm 0.2^{* *}$ \\
\hline
\end{tabular}

$\mathrm{NB} .:$ Each value is the mean of 3 replicates \pm standard error of the mean.

*** Highly significant at $\mathrm{P} \leq 0.001$, ** Significant at $\mathrm{P} \leq 0.01$, *Low significant at $\mathrm{P} \leq 0.05$.

Rats lipids profile at zero time (start) and after 7, 14 and 21 days with normal diet

The results in Table 3 showed serum lipids profile on day 0 and after 7, 14 and 21 days of control group fed on normal diet. Serum cholesterol level showed low insignificant decrease in its level at 21 days (3\%) in comparison with the control.
Triglycerides level (TRI) showed slight increase on days 7 and 21 by 2 and $3.7 \%$, respectively, in comparison with the control rats. HDL showed low significant levels at 14,21 days by $2.5 \%$ in comparison with the control. LDL showed low significant decrease at 21 days by $2.3 \%$ in comparison with the control rats.

Table 3 - Serum lipids profile of rats at zero time and after 7, 14 and 21 days with normal diet (control).

\begin{tabular}{lllll}
\hline Time (day) & Cholesterol & TRI & HDL & LDL \\
\hline 0 & $169 \pm 4.932$ & $95 \pm 2.88$ & $43 \pm 1.527$ & $105 \pm 1.7$ \\
7 & $169 \pm 3.7 *$ & $96.9 \pm * 2.9$ & $43.66 \pm 0.88^{*}$ & $105.33 \pm 1.763^{*}$ \\
14 & $166 \pm 3.05^{*}$ & $94.3 \pm 2.3^{*}$ & $42 \pm 1.154^{*}$ & $104 \pm 2.08^{*}$ \\
21 & $164.6 \pm 3.9^{*}$ & $98.6 \pm 2.3^{*}$ & $42 \pm 1.52^{*}$ & $102.66 \pm 2.96^{*}$ \\
\hline
\end{tabular}

NB.:Each value is the mean of 3 replicates \pm standard error of the mean.

*** Highly significant at $\mathrm{P} \leq 0.001$, ** Significant at $\mathrm{P} \leq 0.01$, * Low significant at $\mathrm{P} \leq 0.05$.

\section{Liver function in rats after 15 days feeding on high fatty diets (Soybean oil and butter)}

Total bilirubin showed increase by $4.3 \%$ with soybean diet and about $5.7 \%$ with butter diet in comparison with the rats fed on normal diet. SGPT showed highly significant increase in its level with soybean diet by $102.7 \%$ and with butter diet by $110.6 \%$ in comparison with the control at normal diet. SGOT showed increase in its level with soybean oil diet by $15.4 \%$ and with butter diet by $47.2 \%$ in comparison with the normal diet. AP level increased with soybean diet and butter diet by 6 and $4.1 \%$, respectively in comparison with the normal diet (Table 4).

Data in Table 5 showed serum lipids in the rats after 15 days feeding on high fatty diets rich in soybean oil and butter. The cholesterol level increased with soybean oil diet by $17.5 \%$ and highly significant increase with butter diet by $104.1 \%$ in comparison with the control with normal diet. TR level showed highly significant increase in its level with soybean oil diet by $153 \%$ and also highly significant increase with butter diet by $157.9 \%$ as compared with the control. HDL showed a significant decrease in its level with 
soybean oil diet by $22.98 \%$ and a significant decrease with butter diet by $25.5 \%$ in comparison with the control. There was highly significant increase in level of low density lipoprotein (LDL) with soybean oil diet by $13.4 \%$ and also highly significant increase with butter diet by $153.4 \%$ in comparison with the control.

Table 4 - Liver function of rats after 15 days feeding by highly fatty diets (Soya bean oil and butter).

\begin{tabular}{llllllll}
\hline Food & Bil T & Bil D & Protein & Albumin & SGPT & SGOT & ALK \\
\hline Normal & $0.72 \pm 0.02^{*}$ & $0.14 \pm 0.01^{*}$ & $7.46 \pm 0.2^{*}$ & $4.26 \pm 0.145^{*}$ & $8.4 \pm 0.3^{*}$ & $7.1 \pm 0.2^{*}$ & $8.9 \pm 0.2^{*}$ \\
Soya bean & $0.74 \pm 0.01^{*}$ & $0.13 \pm 0.01^{*}$ & $7.56 \pm 0.2^{*}$ & $4.26 \pm 0.145^{*}$ & $17.1 \pm 0.4^{* * *}$ & $8.2 \pm 0.2^{* * *}$ & $9.5 \pm 0.3^{*}$ \\
Butter & $0.76 \pm 0.02^{*}$ & $0.15 \pm 0.003^{*}$ & $7.56 \pm 0.2^{*}$ & $4.30 \pm 0.12^{*}$ & $17.8 \pm 0.4^{* * *}$ & $10.5 \pm 0.3^{* * *}$ & $9.3 \pm 0.3^{*}$ \\
\hline
\end{tabular}

NB.:Each value is the mean of 3 replicates \pm standard error of the mean.

*** Highly significant at $\mathrm{P} \leq 0.001$, ** Significant at $\mathrm{P} \leq 0.01$, *Low significant at $\mathrm{P} \leq 0.05$.

Table 5 - Lipids profile of rats serum after 15 days feeding by highly fatty diets (Soya bean oil and butter).

\begin{tabular}{lllll}
\hline Food & Cholesterol & TRI & HDL & LDL \\
\hline Normal & $169 \pm 2.3^{*}$ & $76 \pm 2.01^{*}$ & $45 \pm 1.7^{*}$ & $109.3 \pm 3.1^{*}$ \\
Soya bean & $198.6 \pm 1.9^{* * *}$ & $192.66 \pm 1.5^{* * *}$ & $34.6 \pm 0.8^{* *}$ & $124 \pm 2.08^{* * *}$ \\
Butter & $345 \pm 2.88^{* * *}$ & $196 \pm 2.08^{* * *}$ & $33.3 \pm 0.8^{* *}$ & $277.3 \pm 1.4^{* * *}$ \\
\hline
\end{tabular}

NB.:Each value is the mean of 3 replicates \pm standard error of the mean

*** Highly significant at $\mathrm{P} \leq 0.001$, ** Significant at $\mathrm{P} \leq 0.01$, *Low significant at $\mathrm{P} \leq 0.05$.

The effect of different Spirulina concentrations on liver functions of rats naturally induced hyperlipidemia with $25 \%$ Soya bean oil through 21 days

Data presented in Table 6 showed that in the first week, the liver enzyme SGPT was decreased, while liver albumin increased. After 15 days, more decrease in liver enzyme (SGPT, 8.1u/L) was obtained; the liver albumin was nearly the same. The other changes were insignificant. After three weeks, the SGPT and ALK were decreased but liver albumin was increased.

Table 6 - The effect of the treatment with different Spirulina concentrations on liver functions of rats naturally induced hyperlipidemia with $25 \%$ Soya bean oil through 21 days.

\begin{tabular}{|c|c|c|c|c|c|c|c|}
\hline Spirulina\% & Bil T & Bil D & SGPT & SGOT & Protein & Albumin & ALK \\
\hline & & \multicolumn{6}{|c|}{ Liver functions after one week of treatment } \\
\hline 0.0 & $0.72 \pm 0.01 *$ & $0.14 \pm 0.06^{*}$ & $17 \pm 0.6^{*}$ & $8.3 \pm 0.4^{*}$ & $7.2 \pm 0.2 *$ & $4.4 \pm 0.12 *$ & $8.16 \pm 0.2 *$ \\
\hline 2.5 & $0.71 \pm 0.01 *$ & $0.13 \pm 0.06^{*}$ & $15.7 \pm 0.7 *$ & $7.6 \pm 0.4^{*}$ & $7.8 \pm 0.2 *$ & $4.3 \pm 0.12 *$ & $8.5 \pm 0.3 * *$ \\
\hline 5.0 & $0.70 \pm 0.01 *$ & $0.14 \pm 0.06^{*}$ & $13.7 \pm 0.4^{*}$ & $8.2 \pm 0.3^{*}$ & $7.3 \pm 0.3^{*}$ & $4.5 \pm 0.2 *$ & $8.13 \pm 0.2 *$ \\
\hline 10 & $0.71 \pm 0.01 *$ & $0.13 \pm 0.0 *$ & $13.3 \pm 06 * *$ & $8.2 \pm 0.3^{*}$ & $7.4 \pm 0.2 *$ & $4.6 \pm 0.03 *$ & $8.13 \pm 0.3^{*}$ \\
\hline \multicolumn{8}{|c|}{ Liver functions after two weeks of treatment } \\
\hline 0 & $0.72 \pm 0.01 *$ & $0.14 \pm 0.06^{*}$ & $17.5 \pm 0.6^{*}$ & $8.3 \pm 0.4 *$ & $7.2 \pm 0.2 *$ & $4.4 \pm 0.12 *$ & $8.16 \pm 0.2 *$ \\
\hline 2.5 & $0.72 \pm 0.02 *$ & $0.14 \pm 0.006 *$ & $16 \pm 0.5^{*}$ & $8.1 \pm 0.2 *$ & $7.7 \pm 0.2 *$ & $4.5 \pm 0.1 *$ & $8.4 \pm 0.3 *$ \\
\hline 5 & $0.72 \pm 0.01 *$ & $0.14 \pm 0.006^{*}$ & $12.1 \pm 0.4 *$ & $8.8 \pm 0.2 *$ & $7.6 \pm 0.2 *$ & $4.6 \pm 0.1 *$ & $8.2 \pm 0.3^{*}$ \\
\hline 10 & $0.72 \pm 0.01 *$ & $0.14 \pm 0.006^{*}$ & $8.1 \pm 0.2 * *$ & $8.1 \pm 0.2 *$ & $7.4 \pm 0.2 *$ & $4.6 \pm 0.1 *$ & $8.4 \pm 0.4^{*}$ \\
\hline \multicolumn{8}{|c|}{ Liver functions after three weeks of treatment } \\
\hline 0 & $0.72 \pm 0.01 *$ & $0.14 \pm 0.06^{*}$ & $15 \pm 0.6^{*}$ & $8.3 \pm 0.4^{*}$ & $7.2 \pm 0.2 *$ & $4.4 \pm 0.12 *$ & $8.1 \pm 0.2 *$ \\
\hline 2.5 & $0.7 \pm 0.02 *$ & $0.140 .006^{*}$ & $13 \pm 0.6^{*}$ & $7.01 \pm 0.1 *$ & $7.1 \pm 0.2 *$ & $4.5 \pm 0.1 *$ & $8.4 \pm 0.4 *$ \\
\hline 5 & $0.7 \pm 0.01 *$ & $0.14 \pm 0.006^{*}$ & $12 \pm 0.6^{*}$ & $8.03 \pm 0.2 *$ & $7.2 \pm 0.2 *$ & $4.6 \pm 0.15^{*}$ & $8.3 \pm 0.4 *$ \\
\hline 10 & $0.7 \pm 0.02 *$ & $0.13 \pm 0.006^{*}$ & $8.1 \pm 0.3 *$ & $7.47 \pm 0.2 *$ & $7.6 \pm 0.2 *$ & $4.7 \pm 0.15^{*}$ & $7.6 \pm 0.2 *$ \\
\hline
\end{tabular}

$\mathrm{NB} .:$ Each value is the mean of 3 replicates \pm standard error of the mean.

$* * *$ Highly significant at $\mathrm{P} \leq 0.001$, ** Significant at $\mathrm{P} \leq 0.01$, *Low significant at $\mathrm{P} \leq 0.05$.

The effect of different concentrations of Spirulina on lipid

Table 7 shows the effect of different concentrations of Spirulina on serum lipids in the rats. After one week, the serum the levels of $\mathrm{CHO}$, TRI, and LDL were decreased. A significant decrease was observed after the treatment with $10 \%$ Spirulina. The serum level of HDL was 
increased significantly as compared to the control rats. After two weeks, most of lipids were decreased by increasing the Spirulina doses. In the third week, serum HDL level increased and serum
LDL decreased. The significant changes were observed in most lipids profiles, compared with the control. The serum LDL was decreased with highly significant change at $\mathrm{P} \leq 0.001$.

Table 7 - The effect of three weeks treatment with different Spirulina concentrations on serum lipids profiles of rats naturally induced hyperlipidemia and fatty liver with Soya bean oil.

\begin{tabular}{lllcl}
\hline Spirulina \% & CHO & TRI & HDL & LDL \\
0 & & Serum lipids after one week treatment & \\
2.5 & $200 \pm 5.23^{*}$ & $190.33 \pm 4.91^{*}$ & $40 \pm 1.2^{*}$ & $115.7 \pm 3.5^{*}$ \\
5 & $197.7 \pm 7.8^{*}$ & $187.6 \pm 5.5^{*}$ & $40.7 \pm 1.2^{*}$ & $116 \pm 4.04^{*}$ \\
10 & $183.3 \pm 7.6^{* *}$ & $183 \pm 6.2^{*}$ & $40.7 \pm 1.2^{*}$ & $146.7 \pm 5.8^{* *}$ \\
& $183.7 \pm 5.5^{* *}$ & $179 \pm 5.9^{* *}$ & $43.7 \pm 1.7^{* *}$ & $104.7 \pm 3.2^{* *}$ \\
0 & & Serum lipids after two weeks treatment & $84.7 \pm 2.6^{*}$ \\
2.5 & $275.7 \pm 7.8^{*}$ & $210 \pm 5.2^{*}$ & $38.1 \pm 1.2^{*}$ & $93.7 \pm 3.3^{* *}$ \\
5 & $160 \pm 5.8^{* * *}$ & $119.8 \pm 2.6^{* * *}$ & $45 \pm 1.5^{* *}$ & $95 \pm 3.8^{* *}$ \\
10 & $158 \pm 5.9^{* * *}$ & $91.3 \pm 9.2^{* * *}$ & $42 \pm 1.5^{*}$ & $107 \pm 3.4^{* * *}$ \\
& $156 \pm 4.4^{* * *}$ & $71 \pm 2.1^{* * *}$ & $41 \pm 1.5^{*}$ & $276.3 \pm 4.9^{*}$ \\
0 & & Serum lipids after three weeks treatment & $71.6 \pm 2.03^{*}$ & $82 \pm 2.5^{* * *}$ \\
2.5 & $285.3 \pm 5.8^{*}$ & $207.7 \pm 6.7^{*}$ & $35.6 \pm 1.4^{*}$ & $100 \pm 2.9^{* * *}$ \\
\hline
\end{tabular}

Each value is the mean of 3 replicates \pm standard error of the mean.

*** Highly significant at $\mathrm{P} \leq 0.001$, ** Significant at $\mathrm{P} \leq 0.01$, * Low significant at $\mathrm{P} \leq 0.05$

The effect of different Spirulina concentrations on liver functions of rats naturally induced hyperlipidemia with $25 \%$ butter

Results in Table 8 demonstrated that total and direct bilirubin were slightly changed at 2.5, 5.0 and $10 \%$ Spirulina during three weeks. The liver enzymes were decreased and liver protein and albumin were increased. Alkaline phosphates increased only in the second week and decreased again in the third week. It was observed that the $10 \%$ concentration of Spirulina exhibited the better effect. The change of liver enzyme (SGPT) was highly significant at $\mathrm{P} \leq 0.001$.

The effect of different Spirulina concentrations on lipids of rats naturally induced hyperlipidemia with $25 \%$ Butter through 21 days

Results in Table 9 showed that all the lipids profile decreased by increasing the Spirulina concentration, except HDL. Serum LDL decreased by $13 \%$ less than control at $10 \%$ Spirulina and HDL increased by $23 \%$ more than control. After two weeks of treatment, cholesterol and triglycerides were decreased by 39 and $50 \%$ as compared with the control, respectively. LDL was decreased by $43 \%$ as compared with the control.
Three weeks later, all the lipids profiles were decreased, with the exception of HDL that increased by $53 \%$ more than the control. The changes in the third week were highly significant at $\mathrm{P} \leq 0.001$.

\section{Application on humans}

Data present in Table 10 show liver function of 20 patients with the history of hyperlipidemia at zero time (without treatment) and after 7, 14 and 21 days of treatment with Spirulina. Total bilirubin showed no change after one week of the treatment but after two and three weeks, there was decrease in total bilirubin by $0.1 \%$ in comparison with the control. Direct bilirubin showed decreases after one, two and three weeks of the treatment by $0.9 \%$. Protein concentration showed no change after one week of the treatment but after two and three weeks, it increased by 0.8 and $2.4 \%$, respectively. Albumin level showed no significant change after one, two and three weeks of Spirulina treatment. Alanine Aminotransferase (SGPT) increased after one week of the treatment by $5.3 \%$ but after two and three weeks, there was significant decrease by 12.6 and $16.0 \%$, respectively. Aspartate Aminotransferase (SGOT) increased after one week of the treatment by $1.0 \%$; 
after two weeks, there was decrease by $2.5 \%$ and after three weeks, it increased again by $3.2 \%$. Alkaline phosphatase level showed no changes after one week of the treatment but after two and three weeks, it decreased by 1.0 and by $8.1 \%$, respectively.

Table 8 - The effect of treatment with different Spirulina concentrations on liver functions of rats naturally induced hyperlipidemia with butter during 21 days.

\begin{tabular}{|c|c|c|c|c|c|c|c|}
\hline Spirulina\% & Bil T & Bil D & SGPT & SGOT & Protein & Albumin & ALK \\
\hline \multicolumn{8}{|c|}{ Serum liver function after one week of treatment } \\
\hline 0 & $0.70 \pm 0.01 *$ & $0.15 \pm 0.01 *$ & $19.3 \pm 0.4^{*}$ & $11.8 \pm 0.5 *$ & $7.6 \pm 0.2 *$ & $4.4 \pm 0.2 *$ & $9.2 \pm 0.4 *$ \\
\hline 2.5 & $0.70 \pm 0.01 *$ & $0.14 \pm 0.01 *$ & $17.2 \pm 0.4 *$ & $10.1 \pm 0.4 *$ & $7.7 \pm 0.2 *$ & $4.2 \pm 0.2 *$ & $8.2 \pm 0.2 *$ \\
\hline 5 & $0.70 \pm 0.01 *$ & $0.14 \pm 0.01 *$ & $15.5 \pm 0.3 * *$ & $8.3 \pm 0.4 * *$ & $7.6 \pm 0.2 *$ & $4.4 \pm 0.2 *$ & $9.5 \pm 0.3 *$ \\
\hline 10 & $0.70 \pm 0.02 *$ & $0.12 \pm 0.03 *$ & $13.2 \pm 0.4 * * *$ & $8.2 \pm 0.5 * *$ & $7.5 \pm 0.2 *$ & $4.6 \pm 0.1 *$ & $8.1 \pm 0.2 *$ \\
\hline \multicolumn{8}{|c|}{ Serum liver function after two weeks of treatment } \\
\hline 0 & $0.70 \pm 0.01 *$ & $0.13 \pm 0.003 *$ & $14.4 \pm 0.3 *$ & $8.9 \pm 0.3^{*}$ & $7.6 \pm 0.2 *$ & $4.7 \pm 0.1 *$ & $9 \pm 0.2 *$ \\
\hline 2.5 & $0.69 \pm 0.01 *$ & $0.13 \pm 0.005^{*}$ & $13.1 \pm 0.3 *$ & $7.9 \pm 0.3 *$ & $7.7 \pm 0.1 *$ & $4.6 \pm 0.1 *$ & $10.2 \pm 0.3 *$ \\
\hline 5 & $0.71 \pm 0.01 *$ & $0.15 \pm 0.006^{*}$ & $10.4 \pm 0.1 * *$ & $9.06 \pm 0.3^{*}$ & $6.8 \pm 0.1 *$ & $4.6 \pm 0.1^{*}$ & $9.2 \pm 0.2 *$ \\
\hline 10 & $0.71 \pm 0.01 *$ & $0.14 \pm 0.006^{*}$ & $7.6 \pm 0.2 * *$ & $7.8 \pm 0.2^{*}$ & $7.6 \pm 0.2 *$ & $4.4 \pm 0.1 *$ & $9.06 \pm 0.3 *$ \\
\hline \multicolumn{8}{|c|}{ Serum liver function after three weeks of treatment } \\
\hline 0 & $0.71 \pm .0 .2^{*}$ & $0.12 \pm 0.01 *$ & $17.3 \pm 0.6^{*}$ & $9.9 \pm 0.2^{*}$ & $7.2 \pm 0.2 *$ & $4.6 \pm 0.1 *$ & $9.2 \pm 0.5 *$ \\
\hline 2.5 & $0.71 \pm 0.2 *$ & $0.12 \pm 0.01 *$ & $17.5 \pm 0.5^{*}$ & $8.05 \pm 0.1 * *$ & $7.6 \pm 0.2 *$ & $4.7 \pm 0.1 *$ & $8.6 \pm 0.6^{*}$ \\
\hline 5 & $0.70 \pm 0.02 *$ & $0.11 \pm 0.03 *$ & $8.5 \pm 0.6 * * *$ & $9.2 \pm 0.3 *$ & $7.6 \pm 0.2 *$ & $4.9 \pm 0.1 *$ & $9 \pm 0.4^{*}$ \\
\hline 10 & $0.70 \pm 0.01 *$ & $0.10 \pm 0.03 *$ & $8.6 \pm 0.2 * * *$ & $7.9 \pm 0.2 * *$ & $7.7 \pm 0.2 *$ & $4.9 \pm 0.2 *$ & $7.9 \pm 0.1 *$ \\
\hline
\end{tabular}

Each value is the mean of 3 replicates \pm standard error of the mean.

$* * *$ Highly significant at $\mathrm{P} \leq 0.001$, ** Significant at $\mathrm{P} \leq 0.01$, * Low significant at $\mathrm{P} \leq 0.05$.

Table 9 - The effect of three weeks treatment with different Spirulina concentrations on serum lipids profiles of rats naturally induced hyperlipidemia with butter.

\begin{tabular}{|c|c|c|c|c|}
\hline Spirulina \% & Cholesterol & TRI & HDL & LDL \\
\hline \multicolumn{5}{|c|}{ Serum lipids after one week of treatment } \\
\hline 0 & $358 \pm 7$ & $210.33 \pm 8.95$ & $30.7 \pm 1.2 *$ & $286.7 \pm 8.4$ \\
\hline 2.5 & $294 \pm 7 * * *$ & $206.66 \pm 7.3 *$ & $32 \pm 1.2 *$ & $219.33 \pm 6.9 * * *$ \\
\hline 5 & $280.7 \pm 7 * * *$ & $204 \pm 6.7 *$ & $32.66 \pm 1.2 *$ & $233.33 \pm 3.8^{* *}$ \\
\hline 10 & $270.7 \pm 5.8 * * *$ & $198 \pm 7.7 * *$ & $38 \pm 1.2 * *$ & $192.3 \pm 5.9 * * *$ \\
\hline \multicolumn{5}{|c|}{ Serum lipids after two week of treatment } \\
\hline 0 & $189.4 \pm 4.02$ & $162.5 \pm 4.3$ & $41.5 \pm 1.8$ & $107.3 \pm 4.1$ \\
\hline 2.5 & $182.5 \pm 3.9 *$ & $158.6 \pm 5.8^{*}$ & $42.2 \pm 1.6^{*}$ & $107 \pm 4.2 *$ \\
\hline 5 & $181.0 \pm 6.3 *$ & $119.3 \pm 3.5 * * *$ & $42.2 \pm 1.5^{*}$ & $111.33 \pm 3.5^{*}$ \\
\hline 10 & $116.3 \pm 2.3 * * *$ & $80.9 \pm 3.04 * * *$ & $43.3 \pm 1.5^{*}$ & $61.7 \pm 2.2 * * *$ \\
\hline \multicolumn{5}{|c|}{ Serum lipids after three week of treatment } \\
\hline 0 & $279.7 \pm 7.9$ & $212 \pm 6.01$ & $30.7 \pm 0.9$ & $204 \pm 4.5$ \\
\hline 2.5 & $151.7 \pm 4.4 * * *$ & $143.3 \pm 3.5^{* * *}$ & $41.8 \pm 1.6^{* * *}$ & $79.3 \pm 2.1 * * *$ \\
\hline 5 & $142.7 \pm 4.3 * * *$ & $133.3 \pm 3.4 * * *$ & $45.6 \pm 1.2 * * *$ & $72.03 \pm 1.8 * * *$ \\
\hline 10 & $122.3 \pm 4.3 * * *$ & $107.3 \pm 4.2 * * *$ & $47 \pm 1.1 * * *$ & $52 \pm 1.5 * * *$ \\
\hline
\end{tabular}

Each value is the mean of 3 replicates \pm standard error of the mean.

*** Highly significant at $\mathrm{P} \leq 0.001$, ** Significant at $\mathrm{P} \leq 0.01$, * Low significant at $\mathrm{P} \leq 0.05$

Table 10 -Collective data of liver function of 20 patients with history of hyperlipidemia at zero time (without treatment) and after 7, 14 and 21 days of treatment with Spirulina.

\begin{tabular}{lllllllll}
\hline Days & Bil D & Bil T & SGOT & SGPT & Protein & Albumin & Protein & Alk \\
\hline 0 & $0.15 \pm 0.2^{*}$ & $0.73 \pm 0.4^{*}$ & $47.7 \pm 11.4^{*}$ & $51.4 \pm 9.8^{*}$ & $7.06 \pm 0.1^{*}$ & $4.08 \pm 0.1^{*}$ & $7.06 \pm 0.1^{*}$ & $11.2 \pm 1.2^{*}$ \\
7 & $0.14 \pm 0.1^{* *}$ & $0.73 \pm 0.4^{*}$ & $48.1 \pm 9.7^{*}$ & $54.1 \pm 8.6^{*}$ & $7.06 \pm 3.2^{*}$ & $4.08 \pm 0.08^{*}$ & $7.06 \pm 3.2^{*}$ & $11.2 \pm 1.2^{*}$ \\
14 & $0.13 \pm 0.1^{* *}$ & $0.72 \pm 0.3^{*}$ & $46.5 \pm 9.7^{*}$ & $44.9 \pm 5.8^{* *}$ & $7.1 \pm 0.1^{*}$ & $4.1 \pm 0.07^{*}$ & $7.1 \pm 0.1^{*}$ & $11.1 \pm 1.1^{*}$ \\
21 & $0.13 \pm 1.4^{* *}$ & $0.72 \pm 1.5^{*}$ & $49.2 \pm 6.7^{*}$ & $38.0 \pm 4.8^{* *}$ & $7.2 \pm 0.1^{*}$ & $4.1 \pm 0.1^{*}$ & $7.2 \pm 0.1^{*}$ & $10.2 \pm 1.09^{*}$ \\
\hline
\end{tabular}

NB.:Each value is the mean \pm standard error of the mean.

*** Highly significant at $\mathrm{P} \leq 0.001$, ** Significant at $\mathrm{P} \leq 0.01$, *Low significant at $\mathrm{P} \leq 0.05$. 
As evident from Table 11, serum cholesterol level showed highly significant decrease after one, two and three weeks with Spirulina treatment (15.12, 23.9 and $28.44 \%$, respectively). Triglycerides level showed highly significant decrease by $10.6,20.5$ and $31.6 \%$ after one, two and three weeks, respectively with the treatment. High density lipoprotein level increased significantly by 7.5 , 22.0 and $28.0 \%$ after one, two and three weeks, respectively. Low density lipoprotein level showed highly significant decrease after one, two and three weeks and was $19.9,32.2$ and $37.7 \%$, respectively.

Table 11 - Collective data of Serum lipids profile of 20 patients with history of hyperlipidemia at zero time (without treatment) and after (7, 14 and 21 days) of treatment with Spirulina.

\begin{tabular}{ccccc}
\hline Days & Cholesterol & TRI & HDL & LDL \\
\hline 0 & $257.9 \pm$ & $155.2 \pm$ & $36.8 \pm$ & $190.4 \pm$ \\
& $7.3 *$ & $20.7 *$ & $0.6 *$ & $7.6 *$ \\
7 & $218.9 \pm$ & $138.7 \pm$ & $39.5 \pm$ & $154.2 \pm$ \\
& $6.3 * * *$ & $20.6 * * *$ & $0.7 * *$ & $6.3 * * *$ \\
14 & $196.2 \pm$ & $123.4 \pm 2$ & $44.9 \pm$ & $129.3 \pm$ \\
& $7.7 * * *$ & $0.6 * * *$ & $2.6 * * *$ & $5.1 * * *$ \\
21 & $184.5 \pm$ & $106.1 \pm$ & $47.1 \pm$ & $118.6 \pm$ \\
& $7.09 * * *$ & $16.4 * * *$ & $1.3 * * *$ & $5.6 * * *$ \\
\hline
\end{tabular}

NB.:Each value is the mean \pm standard error of the mean.

*** Highly significant at $\mathrm{P} \leq 0.001$, ** Significant at $\mathrm{P} \leq 0.01$, *Low significant at $\mathrm{P} \leq 0.05$.

\section{DISCUSSION}

Spirulina is cultivated around the world and is used as a human dietary supplement as well as a whole food and is available in form of the tablet, flake, and powder. It is also used as a food supplement in the aquaculture, aquarium, and poultry industries (Wang et al. 2005). There is scientific and clinical evidence for its nutritional value and for its potential health benefits. These benefits attracted its use as a functional food in addition to its already established use as a dietary supplement (Lee 1997; Belay 2002).

The results of the present study showed low significant levels of functional changes in comparison with the control; on the other hand the serum lipids profiles changed after one week of treatment of naturally induced hyperlipidemia with soybean oil. Administration of different Spirulina concentrations resulted in significant decreases in total cholesterol, triglyceride and LDL and significant increase in HDL at 5 and $10 \%$ of Spirulina. A highly significant decrease in total cholesterol, triglyceride and LDL and highly significant increase in HDL at all Spirulina concentrations were obtained in the humans and rats. Significant reductions in the triglycerides, total cholesterol, and its fractions, except high density lipoprotein cholesterol (HDL-C) were observed after supplementation of Spirulina (Nakaya et al. 1988). Insignificant changes ( $p$ $<0.05)$ of liver functions were obtained from soybean oil and butter. The serum cholesterol of the rats fed by oil and butter was increased. The butter gave the highest effect compared with the normal diet. The results showed that liver function and serum lipids profile changed after 15 days with feeding by highly fatty diets (soybean oil and butter); changes of SGPT and SGOT showed highly significant increases. Serum lipids profile (serum cholesterol level, triglycerides and low density lipoprotein) were significantly increased after 15 days after feeding with high fat diets, i.e., soybean oil and butter as compared with the normal diet (Torres-Durana et al. 1999).

In line with previous results (González de Rivera et al. 1993), the present results indicated that Spirulina prevented the dietary hypercholesterolemia and arteriosclerosis in the humans. Several reports also suggested that Spirulina could have a beneficial effect in the prevention of hypercholesterolemic cardiovascular diseases (Juárez-Oropeza et al. 2009).

Spirulina reduces the level of lipids by reducing cholesterol and serum triacylglycerol levels, where it increased the levels of HDL and decreased LDL. SGPT and SGOT were decreased by increasing the dose of Spirulina with time. Becker et al. (1986) and Nakaya et al. (1988) reported that Spirulina reduced serum cholesterol $(4.5 \%)$, triacylglycerol and LDL when volunteers were given $4 \mathrm{~g}^{\text {day }}{ }^{-1}$ oral dose. In line with these studies, Spirulina $\left(4.2 \mathrm{~g} \mathrm{day}^{-1}\right)$ was added for eight weeks to the diet of 30 Japanese males with high cholesterol, mild hypertension, and hyperlipidemia. Spirulina resulted significant changes in cholesterol and blood pressure, lowered total cholesterol, increased HDL cholesterol, lowered triglycerides, and lowered systolic and diastolic blood pressure (Torres-Duran et al. 2007). A study with diabetic rats concluded that Spirulina maxima was effective in correcting the abnormal carbohydrate and lipid metabolisms caused by the excess of fructose within the body (Kulshreshtha et al. 2008). 
In conclusion Spirulina reduced the level of lipids by reducing serum cholesterol and serum triacylglycerol levels. Spirulina increased the HDL and decreased LDL and corrected liver function, especially alanine aminotransferase (SGPT) and aminotransferase (SGOT).

\section{REFERENCES}

Adams LA, Talwalkar, J.A. Diagnostic evaluation of nonalcoholic fatty liver disease, J Clin Gastroenterol. 2006; 40: 34-65.

Altlparmak E, Koklu S, Yallnklllc M, Yuksel O, Cicek B, Kayacetin E, Sahin, T. Viral and host causes of fatty liver in chronic hepatitis B. World $J$ Gastroenterol. 2005; 11: 3056-3059.

Babadzhanov AS, Abdusamatova N, Yusupova FM, Faizullaeva N, Mezhlumyan LG, Malikova MK. Chemical composition of Spirulina platensis cultivated in uzbekistan. Chem Natur Comp. 2004; 40(3): 276-279.

Bayard M, Holt J, Boroughs E. Nonalcoholic fatty liver disease. Am Fam Physician. 2006, 73 (11): 19611968.

Becker EW, Jakober B, Luft D. Clinical and biochemical evaluations of the alga Spirulina with regard to its application in the treatment of obesity. A double-blind cross over study. Nutr Rep Intern.1986; 33:565-573.

Belay A. The potential application of Spirulina (Arthrospira) as a nutritional and therapeutic supplement in health management. $J$ Am Nutraceut Assoc. 2002; 5(2): 27-48.

Boekholdt SM. Value of low-density lipoprotein particle number and size as predictors of coronary artery disease in apparently healthy men and women: the EPIC-Norfolk Prospective Population Study. $J$ Amer Nutraceut Assoc. 2007; 49: 547-533.

Buccolo G, David H. Quantitative determination of serum triglycerides by use enzymes. Clin Chem.1973; 19 (5): 476-482.

Burstein M, Scholnick, H.R., Morfin, R. Severe combined hyperlipidemia. Scand J Clin Lab Invest. 1980; 40: 560-572.

Burtis A. Clinical and experimental study of Spirulina. Tietz Textbook of Clinical Chemistry, 1999; 3rd ed AACC.

Carroll MD, Lacher DA, Sorlie PD, Cleeman, JI, Gordon DJ, Wolz, M, Grundy SM, Johnson CL. Trends in serum lipids and lipoproteins of adults, 1960-2002. JAMA. 2005; 294(14): 1773-1781.

Chen LL, Blé-Castillo JL, Juárez-Oropeza MA, DíazZagoya JC. Experimental study of Spirulina platensis in treating allergic rhinitis in rats. J Central South Univ (Medical Sciences) 2005; 30(1): 96-98.
Doherty JF, Golden, MH, Brooks SE: Peroxisomes and the fatty liver of malnutrition: A hypothesis. Am J Clin Nutr. 1991; 54: 674.

Finley PR, Schifman RB, Williams RJ, Lichti DA: Cholesterol in high-density lipoprotein: use of $\mathrm{Mg} 2+/$ dextran sulfate in its enzymic measurement. Clin Chem. 1978; 24: 931-933.

Fischbach F, Zawta B. Age-dependent reference limits of several enzymes in plasma at different measurement temperatures. Klin Lab. 1992; 38: 555561.

González de Rivera C, Miranda-Zamora R, DíazZagoya JC, Juárez-Oropeza MA. Preventive effect of Spirulina maxima on the fatty liver induced by a fructose-rich diet in the rat, a preliminary report. Orig Res Article Life Sci. 1993; 53 (1): 57-61.

Guha-Mazumder DN: Arsenic and liver disease, $J$ Ind Medic Assoc. 2001, 9: 311-324.

Huang Z, Guo BJ, Wong RNS, Jiang Y. Characterization and antioxidant activity of seleniumcontaining phycocyanin isolated from Spirulina platensis. Food Chem. 2007; 100(3): 1137-1143.

James, WD, Berger G, Timothy G. Andrews' Diseases of the Skin: clinical Dermatology, 2 nd edition, 2006.

Juárez-Oropeza MA, Mascher D, Torres-Durán PV, Farias JM, Paredes-Carbajal MC. Effects of dietary Spirulina on vascular reactivity. J Med Food. 2009; 12(1): 15-20

Khan M, Shobha JC, Mohan IK, Naidu MU, Sundaram C, Singh S, Kuppusamy P, Kutala VK. Protective effect of Spirulina against doxorubicininduced cardiotoxicity. Photother Res. 2005; 19(12): 10301047.

Kulshreshtha A, Zacharia AJ, Jarouliya U, Bhadauriya P, Prasad GB, Bisen PS. Spirulina in health care management. Curr Pharmaceut Biotechnol. 2008; 9 (5): 400-405.

Lee YK. Commercial production of microalgae in the Asia-Pacific rim. J Appl Phycol. 1997; 9: 403-411.

Lewington S, Whitlock, G., Clarke, R. Blood cholesterol and vascular mortality by age, sex, and blood pressure: a meta-analysis of individual data from 61 prospective studies with 55,000 vascular deaths. Lancet. 2007; 370:1829-1842.

Malloy HT, Evelyn KA. The determination of bilirubin with the photoelectric colorimeter. J Biol Chem. 1937; 119: 481-490.

Nakaya N, Homma Y, Goto Y. Cholesterol lowering effect of Spirulina. Nutr Rep Intern. 1988; 37:132937.

Rader, DJ, Hoeg JM, Brewer HB. Quantitation of plasma apolipoproteins in the primary and secondary prevention of coronary artery disease. Annals Internal Medicine. 1994; 120:1012-1033.

Reddy JK, Rao MS. Lipid metabolism and liver inflammation, Fatty liver disease and fatty acid oxidation. Amer J Physiol-Gastroint Liver. 2006; 290 (5): 852-858. 
Riely CA. Acute fatty liver of pregnancy. Semin Liver Dis. 1987; 7(1): 47-54.

Rodkey FL. Tris (hydroxymethyl) Aminomethane as a standard for kjeldahl nitrogen analysis. Clin Chem. 1964; 10: 606-610.

Sánchez M. Spirulina (Arthrospira): An edible microorganism, a review 2007; http://www.javeriana.edu.co/universitas_scientiarum/ vol8n1/J_bernal.htm.

Schumann G, Bonora R, Ceriotti F. IFCC primary reference procedures for the measurement of catalytic activity concentrations of enzymes at 37 degrees C. International Federation of Clinical Chemistry and Laboratory Medicine, Part-5, Reference procedure for the measurement of catalytic concentration of aspartate aminotransferase. Clin Chem Lab Med. 2002; 40: 725-733.

Schumann G, Klauke R. New IFCC reference procedures for the determination of catalytic activity concentrations of five enzymes in serum: preliminary upper reference limits obtained in hospitalized subjects. Clinica Chim Acta. 2003; 327: 69-79.

Shattat G, Al-Qirim T, Sweidan K, Shahwan M, ElHuneidi W, Al-Hiari Y. The hypolipidemic activity of novel benzofuran-2-carboxamide derivatives in Triton WR-1339-induced hyperlipidemic rats: a comparison with bezafibrate. J Enzyme Inhibit Medic Chem. 2010, 25(6): 751-755

Tokusoglu O, Uunal MK. Biomass Nutrient Profiles of three Microalgae: Spirulina platensis, Chlorella vulgaris, and Isochrisis galbana. J Food Science. 2003; 68 (4): 1144-1148.
Torres-Duran PV, Hermosillo F, Oropeza J. Antihyperlipidemic and antihypertensive effects of Spirulina maxima in an open sample of Mexican population: A preliminary report. Lipids Health Dis. 2007; 6: 33-49.

Torres-Duran PV, Miranda-Zamora R, ParedesCarbajal MC, Mascher D, Diaz-Zagoya JC, Oropeza J. Studies on the preventive effect of Spirulina maxima on fatty liver development induced by carbon tetrachloride in the rat. J Ethnopharmacol. 1999; 64 (2): 141-147.

Vonshak A. Spirulina platensis (Arthrospira), Physiology, Cell-biology and Biotechnology. 1997; London: Taylor \& Francis.

Walters MI, Gerarde H. Pharmaceutical chemistry, Volume 2. Microchem J. 1970; 15(1): 150-155.

Wang Y, Chang C, Chou J, Chen H, Deng X, Harvey BK, Cadet JL, Bickford PC. Dietary supplementation with blueberries, spinach, or Spirulina reduces ischemic brain damage. Experim Neurol. 2005; 193(1) : 75-84.

Wu LL, Warnick GR, Wu JT, Williams RR, Lalouel JM. A rapid micro-scale procedure for determination of the total lipid profile. Clin Chem. 1989; 35: 14861491.

Young DS: Effects of disease on Clinical Lab. Tests 2001, 4th ed AACC.

Zarrouk C. Contribution a 1 etude d une cyanophycee influence dedivers facteurs physiques et chimiques sur la croissance et photosynthese de Spirulina maxima. Geither, Ph.D. Thesis, pp 4-8World Rev. Nutr Diet. 1966; 77: 32-46. 